\title{
Hybrid composites of mesenchymal stem cell sheets, hydroxyapatite, and platelet-rich fibrin granules for bone regeneration in a rabbit calvarial critical-size defect model
}

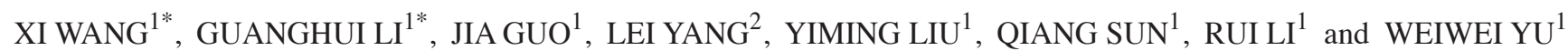 \\ ${ }^{1}$ Department of Stomatology, The First Affiliated Hospital of Zhengzhou University, Zhengzhou, \\ Henan 450052; ${ }^{2}$ Department of Orthodontics, Beijing Ruitai Dental Hospital, Beijing 100107, P.R. China
}

Received October 14, 2015; Accepted January 13, 2017

DOI: $10.3892 /$ etm.2017.4199

\begin{abstract}
The reconstruction of large bone defects remains a major clinical challenge, and tissue engineering is a promising technique for resolving this problem. Many attempts have been made to optimize bone tissue engineering protocols. The aim of the present study was to develop a process incorporating mesenchymal stem cell (MSC) sheets with nanoscale hydroxyapatite (nano-HA) and autologous platelet-rich fibrin (PRF) granules for enhanced bone formation within a critical-sized rabbit cranial defect. MSC sheets and PRF were prepared prior to in vivo experiments. The osteogenic differentiation ability of MSCs and the ultrastructure of PRF were also studied. A total of 15 New Zealand white rabbits were used in the current study and critical-size defects (CSDs) were surgically introduced in the cranium (diameter, $15 \mathrm{~mm}$ ). The surgical defects were treated with MSC/PRF composites, MSC composites or left empty. Animals were euthanized at week 8 post-surgery. Iconography, histological and histomorphometric analysis were performed to assess de novo bone formation. The percentage of new bone in the MSC/PRF group $(35.7 \pm 5.1 \%)$ was significantly higher than that in the MSC $(18.3 \pm 3.2 \%$; $\mathrm{P}<0.05)$ and empty defect groups $(4.7 \pm 1.5 \%$; $\mathrm{P}<0.05)$. The results of the present study suggest that combined application of an MSC sheet with nano-HA and granular PRF enhances bone regeneration in a rabbit calvarial CSD model, and provides a novel insight into bone tissue regeneration for large bone defects.
\end{abstract}

Correspondence to: Professor Weiwei Yu or Dr Rui Li, Department of Stomatology, The First Affiliated Hospital of Zhengzhou University, 1 East Jian She Road, Zhengzhou, Henan 450052, P.R. China

E-mail: ywwzd2015@163.com

E-mail: liruisichuan@163.com

*Contributed equally

Key words: mesenchymal stem cells, cell sheet, platelet-rich fibrin, bone regeneration, rabbit calvarial critical-size defect

\section{Introduction}

The repair of large segments of defective bone is frequently necessary in oral, maxillofacial, orthopedic, plastic and reconstructive surgery $(1,2)$. The challenges in treating large bone defects lie in designing devices and biomaterials that are able to foster the bone wound healing process into the appropriate pathway that leads toward the complete regeneration of the missing tissue (3). Autologous bone or allografts to repair large bone defects have significant limitations in terms of availability, morbidity, efficacy, immunological reactions and disease transmission $(4,5)$. Tissue engineering is a promising alternative approach that permits the efficient reconstruction of bone defects through use of three main components: Multipotent stem cells, scaffolds to direct tissue development and utilization of tissue-inducing substances such as growth factors (6).

Among many available sources, mesenchymal stem cells (MSCs) derived from bone marrow (BMSCs) are typically used as multipotent autologous cell sources for bone tissue engineering (7). BMSCs may be collected via relatively noninvasive methods and provide osteoblasts to support the process of bone remodeling under physiological conditions (8). A number of previous studies have demonstrated the advantages of using MSCs for the regeneration of bone (9-11). Furthermore, MSCs have been applied clinically for $>10$ years (12). The results of clinical trials have demonstrated the efficacy of bone tissue engineering using BMSCs, and their clinical use appears to be relatively safe (12-14).

Scaffolds used for tissue engineering applications are typically biocompatible and biodegradable, support cell proliferation and differentiation, and are able to provide appropriate mechanical support (15). Cell sheet engineering, as a novel tissue engineering technique, recreates a biological microenvironment similar to that of a regenerative milieu (16). Without typical proteolytic enzyme or EDTA treatments, cultured cells are able to be harvested as a single contiguous cell sheet, retaining cell-cell junctions, as well as deposited extracellular matrix (ECM) on the basal sheet surface (17). Many research groups have reported bone formation or regeneration by the cell sheet itself $(18,19)$. Synthetic bone substitutes such as hydroxyapatite (HA), $\beta$-tricalcium phosphate and combinations 
of these have been used for bone tissue engineering $(20,21)$. Recent advances in nanoscience and nanotechnology have reignited interest in the formation of nanosized HA and the study of its properties on the nanoscale (15). It has been reported that nanocrystalline hydroxyapatite (nano-HA) powder exhibited improved mechanical properties and better bioactivity compared with coarser crystals $(22,23)$. Based on these findings, composites of cell sheets and nano-HA may be a suitable candidate material for bone tissue engineering.

Growth factors are also expected to serve a significant role in bone tissue engineering. Platelet concentrates have previously been used as a source of growth factors in many studies of bone regeneration (24-26). Platelet-rich fibrin (PRF) has been referred to as the second-generation platelet concentrate, which has been demonstrated to have several advantages over traditionally prepared platelet-rich plasma including ease of preparation and no biochemical handling of blood $(27,28)$. The autologous origin of PRF does not lead to any risk of immunologic reaction or transmissible diseases (28). Platelets contain a variety of active growth factors, which are able to stimulate wound healing and bone formation $(29,30)$. PRF is defined as a leukocyte-rich and platelet-rich fibrin biomaterial (31), and it has previously been hypothesized that leukocytes are able to influence cell reactions and growth factor release (32).

In the present study, it was hypothesized that a bone tissue engineering strategy consisting of an MSC sheet, nano-HA and PRF granules may be able to repair critical-size bone defects in a rabbit model. This bone graft method, based on tissue engineering concepts, may reveal novel opportunities for the clinical treatment of large bone defects.

\section{Materials and methods}

Isolation of mesenchymal stem cells from bone marrow. Animals were anesthetized with an intravenous injection of $100 \mathrm{mg} / \mathrm{kg}$ sodium barbiturate (Sigma-Aldrich; Merck KGaA, Darmstadt, Germany). Bone marrow was subsequently aspirated from the hind limb bones under sterile conditions. MSCs were isolated from the aspirated bone marrow using the Percoll density gradient centrifugation method (Histopaque-1077; Sigma-Aldrich; Merck KGaA) and were cultured in $\alpha$-Minimum Essential Medium ( $\alpha$-MEM; Gibco; Thermo Fisher Scientific, Inc., Waltham, MA, USA) supplemented with $10 \%$ fetal bovine serum (FBS; Gibco; Thermo Fisher Scientific, Inc.), 2 mM L-glutamine (Invitrogen; Thermo Fisher Scientific, Inc.), $100 \mathrm{U} / \mathrm{ml}$ penicillin and $100 \mathrm{mg} / \mathrm{ml}$ streptomycin (Gibco; Thermo Fisher Scientific, Inc.) in a humidified atmosphere containing $5 \% \mathrm{CO}_{2}$ at $37^{\circ} \mathrm{C}$. The culture medium was changed twice per week. When MSCs reached 80-90\% confluence, they were trypsinized and re-seeded for further expansion.

Induction of osteogenic differentiation of MSCs in vitro. In total, $1 \times 10^{5}$ MSCs were seeded into each well of 6-well plates and cultured in $\alpha$-MEM supplemented with $10 \%$ FBS, $2 \mathrm{mM}$ L-glutamine, $100 \mathrm{U} / \mathrm{ml}$ penicillin and $100 \mathrm{mg} / \mathrm{ml}$ streptomycin in a humidified atmosphere containing $5 \% \mathrm{CO}_{2}$ at $37^{\circ} \mathrm{C}$. When cells reached $80 \%$ confluence, MSCs were cultured in $\alpha$-MEM supplemented with $10 \%$ FBS, 2 mM L-glutamine, $100 \mathrm{nM}$ dexamethasone (Sigma-Aldrich; Merck KGaA), $50 \mu \mathrm{g} / \mathrm{ml}$ of ascorbic acid, and $5 \mathrm{mM} \beta$-glycerophosphate (Sigma-Aldrich; Merck KGaA) to induce osteoblast differentiation. The media were changed every two days. Alkaline phosphatase (ALP) staining was performed using a 5-bromo-4-chloro-3-indolyl phosphate/nitro blue tetrazolium alkaline phosphatase color development kit (Beyotime Institute of Biotechnology, Haimen, China) following 7 days of culture according to the manufacturer's protocols. Following 21 days of culture with the osteogenic supplements, the cells were washed twice PBS (Beyotime Institute of Biotechnology, Haimen, Jiangsu, China), fixed in a $70 \%$ ethanol solution for $1 \mathrm{~h}$ at $37^{\circ} \mathrm{C}$, then stained with Alizarin red to reveal mineralized nodules. Cells were subsequently washed with PBS, and observed and imaged using an inverted microscope.

Construction of cell sheets. Cell sheets were prepared as previously reported (33). To create the cell sheet, MSCs were seeded at $2.5 \times 10^{4}$ cells $/ \mathrm{cm}^{2}$ in $9-\mathrm{cm}$ culture plates for subculture at $37^{\circ} \mathrm{C}$ with $10 \mathrm{nM}$ dexamethasone and $50 \mu \mathrm{g} / \mathrm{ml}$ ascorbic acid until reaching $80 \%$ confluence on day 14 . The medium was changed every 2 days.

PRF preparation. A total of $10 \mathrm{ml}$ of autologous whole blood was harvested from the central ear artery of each rabbit. Blood samples were treated according to the PRF protocol (34). Briefly, the blood sample was transferred into a $10 \mathrm{ml}$ glass tube without anticoagulants. The tube was immediately centrifuged at $400 \mathrm{x} \mathrm{g}$ for $10 \mathrm{~min}$ at room temperature. A fibrin clot was obtained in the middle of the tube, which was easily separated from the red corpuscles at the bottom and the acellular plasma at the top of the tube (Fig. 1A). Following compression with sterile dry gauze, the fluids trapped in the fibrin matrix were driven out, and the clot became a very resistant autologous fibrin membrane (Fig. 1B and C). The obtained membrane was cut into small granules with sizes of up to $1 \mathrm{~mm}^{3}$ using sterile scissors (Fig. 1D) for the following in vivo experiment.

Scanning electron microscopy (SEM) analysis. To identify the ultrastructure of the PRF, the specimens of PRF membrane were fixed with a solution of $2.5 \%$ glutaraldehyde (Hubei Shengtian Hengchuang Biotechnology Co., Ltd., Wuhan, China) at $4^{\circ} \mathrm{C}$ for $1 \mathrm{~h}$ and subsequently dehydrated using graded ethanol, as previously described (35). Images were captured using SEM (S-4800; Hitachi, Ltd., Tokyo, Japan).

Animals. A total of 15 male New Zealand rabbits (Zhongchuang Biotechnology Co., Ltd., Guangzhou, China), aged 3-5 months and with a mean weight of $3.1 \mathrm{~kg}$, were used in the present study. All experiments were performed following the guidelines of the Chinese government for the care and use of laboratory animals (http://scitech.people. com.cn/GB/126054/139095/8378670.html). All protocols were approved by the Animal Welfare Committee of Zhengzhou University. The rabbits were housed in a temperature-controlled room $\left(21-23^{\circ} \mathrm{C}\right)$ and maintained under a $12 \mathrm{~h}$ light-dark cycle. Each rabbit was housed in an individual cage and fed a standard dried diet and water ad libitum. Commercially available nano-HA powder (Sigma-Aldrich; Merck KGaA) was sterilized using ${ }^{60} \mathrm{Co}$ irradiation. For ectopic transplantation, $100 \mathrm{mg}$ nano-HA was wrapped in a 
A

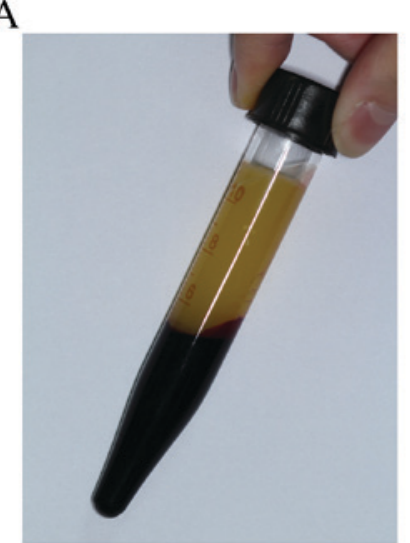

$\mathrm{C}$

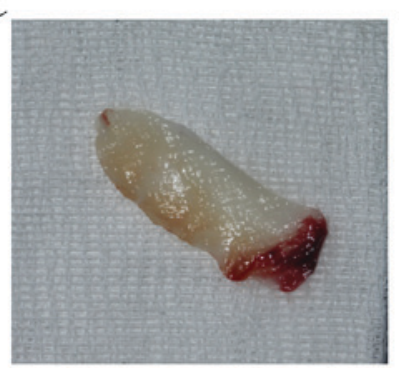

B

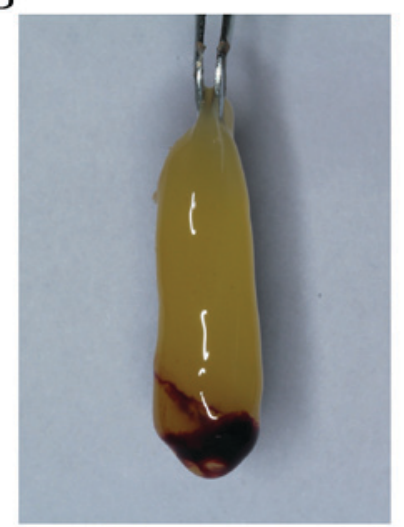

$\mathrm{D}$

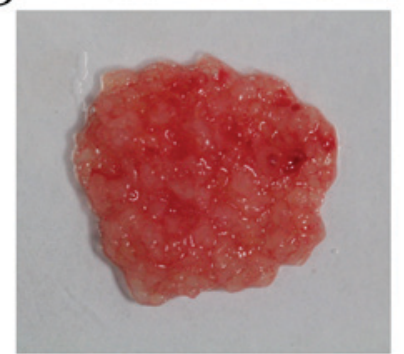

Figure 1. PRF clot and PRF granules. (A) The PRF clot is located in the middle of the tube following centrifugation. (B) Collected PRF fraction. (C) Generation of resistant PRF membrane following removal of the liquid (D) PRF membrane cut into small granules prior to the in vivo experiment. PRF, platelet-rich fibrin.

piece of cell sheet with or without autologous PRF granules to generate a composite. Rabbits were randomly divided into three groups: $\mathrm{MSC} / \mathrm{PRF}(\mathrm{n}=6), \mathrm{MSC}(\mathrm{n}=6)$ and control groups $(\mathrm{n}=3)$. In the MSC/PRF group, defects were repaired using MSC/PRF composites with $100 \mathrm{mg}$ nano-HA, as mentioned above. In the MSC group, defects were repaired with the MSC composites, also with $100 \mathrm{mg}$ nano-HA. In the control group, defects were untreated.

Surgical procedure. All rabbits were anesthetized with an intravenous injection of $100 \mathrm{mg} / \mathrm{kg}$ sodium barbiturate (Sigma-Aldrich; Merck KGaA). The surgical region was shaved and aseptically prepared, with sterile barriers to limit the surgical field. A tongue-shaped incision was made over the head and the skin, and underlying tissues, including the temporal muscle, were subsequently retracted to expose the full extent of the cranium. The periosteum was resected to avoid any influence on bony regeneration. A $15-\mathrm{mm}$ diameter full-thickness defect, which was demonstrated to be the critical-size defect (CSD) in previous studies $(36,37)$, was carefully prepared to avoid dural tears using a dental bar and continuous irrigation with sterile saline at room temperature. Rabbits were subsequently administered with their respective treatments. The scalp was repositioned and sutured to achieve primary closure. Each rabbit received a prophylactic intramuscular injection of penicillin $(25,000 \mathrm{IU} / \mathrm{kg})$.

Computerized tomography. All rabbits were subjected to postoperative computerized tomography (CT) examinations at 4, 6 and 8 weeks post-surgery. CT image acquisition, processing,

and manipulation were performed according to the standard protocol of Zhengzhou University (Zhengzhou, China). CT data were reconstructed into three-dimensional (3D) images using CT included software (AW Basic Display ver. 4.1; GE Healthcare Life Sciences, Chalfont, UK). The craniofacial bone was extracted from the 3D CT images with the threshold adjusted to remove the soft tissue and display the bone.

Bone histological and histomorphometric analysis. At 8 weeks post-surgery, rabbits were euthanized humanely with an intravenous overdose of sodium barbiturate (Sigma-Aldrich; Merck $\mathrm{kGaA})(200 \mathrm{mg} / \mathrm{kg})$. Calvaria were harvested, decalcified in $10 \%$ formic acid and subsequently embedded in paraffin. Serial sections of $5-\mu \mathrm{m}$ thickness were cut perpendicular to the mid-sagittal suture from the center of each defect using a microtome (RM2155; Leica Microsystems GmbH, Wetzlar, Germany) and stained with hematoxylin and eosin. The section displaying the widest defect area was selected. Digital images of the selected sections were captured using a light microscope at x5 magnification (DM16000; Leica Microsystems GmbH). New bone formation within the defect was calculated histomorphometrically using Image-Pro Plus 7.0 software (Media Cybernetics, Inc., Rockville, MD, USA). The percentage of new bone was calculated by dividing the bone area by the whole defect area. All data were collected and analyzed by an independent investigator to reduce bias and errors.

Statistical analysis. Data analysis was conducted using SPSS version 17.0 software (SPSS, Inc., Chicago, IL, USA). All data are presented as the mean \pm standard deviation. Comparisons between groups were performed using the Student's $t$-test following a homogeneity test of variance. $\mathrm{P}<0.05$ was considered to indicate a statistically significant difference.

\section{Results}

Osteogenic differentiation ability. The osteogenic differentiation capacity was studied after 7-21 days of culture under osteogenic culture conditions. ALP, which catalyzes hydrolysis of phosphate esters at an alkaline $\mathrm{pH}$, is a well-known enzyme used as a marker of the osteogenic phenotype (19). The morphology of MSCs prior to osteogenic differentiation was recorded (Fig. 2A). In osteo-induced MSCs, ALP staining revealed high ALP activity (Fig. 2B). Alizarin red S staining also revealed a marked osteogenic differentiation capacity (Fig. 2C). These findings indicated that cultured MSCs were able to differentiate into functional osteoblast-like cells in vitro.

Fabrication of cell sheets. With $10 \mathrm{nM}$ dexamethasone and $50 \mu \mathrm{g} / \mathrm{ml}$ ascorbic acid stimulation, MSCs exhibited an increase in the synthesis of extracellular matrix and formed dense cell sheets. Following 14 days of culture, cells were washed twice with PBS. Intact cell sheets were subsequently able to be detached using a cell scraper (Fig. 2D) and further manipulated for wrapping with PRF/HA or HA alone.

Ultrastructure of the PRF. SEM observation of the PRF clot revealed a scaffold appearance, which contained randomly arranged fibrillar elements of almost homogeneous thickness, 
constituting a 3D network (Fig. 3A). In the lower region of the fibrin clot in particular, platelets, leukocytes and red blood cells were embedded in the network (Fig. 3B). It appeared, therefore, that the lower region of the PRF was more suitable for clinical application.

Gross morphology of bone regeneration in rabbits. All rabbits tolerated the anesthesia and the surgical procedures well and experienced no complications during the experimental period. There was no evidence of wound infection or dehiscence from the implantation. The implants were well integrated into the surrounding calvarial bone, and the defects were closed. Palpation of the defects revealed that tight bone-like structures filled the defect in the MSC/PRF and MSC groups. There were no obvious macroscopic differences between the two experimental groups. In the control group, all empty defects were occupied with soft consistency tissue and no bone filling was detected by palpation or exploration.

$3 D$ CT reconstruction results. Representative $3 \mathrm{D}$ CT images from each group are presented in Fig. 4. Although a lower radiodensity area was observed in part of the calvarium, almost complete union was observed throughout the defect in the group implanted with MSC/PRF composite, suggesting that substantial levels of new bone were formed in the defect site. Most of area was occupied by bone-like structures in the defect filled with PRF composite; however, the center of the defect was still radiolucent, which suggests less bone formation. In the control group, bone formation close to the borders of the surrounding host calvarial bone was observed, suggesting the lowest amount of bone formation of the three groups.

Histological results. Similar to the results obtained from 3D CT data, the histological examination revealed variable amounts of calcification in the defect sites of the calvarial specimens. Representative histologic images for each group are presented in Fig. 5, with yellow arrows indicating the sites of defect and blue/black arrows showing typical regenerative tissue. In the MSC/PRF group, bony bridging and new bone formation was observed throughout the center and the edges of the defect. However, in the MSC group, relatively sparser bone formation was observed, in particular at the center of the defect. In the control group, fibrous tissues alone were observed in the defect area, with a small amount of new bone formation at the defect margins. The extent of new bone formation (\% new bone area) in each group was evaluated using Image-Pro Plus software. The amount of new bone was significantly greater in the MSC/PRF group (35.7 $\pm 5.1 \%)$ compared with the MSC group $(18.3 \pm 3.2 \%$; $\mathrm{P}<0.05$; Fig. 6$)$. The percentage of new bone in the MSC/PRF group was also significantly higher than that in the control groups $(4.7 \pm 1.5 \%$; $\mathrm{P}<0.05$, Fig. 6).

\section{Discussion}

The reconstruction of large bone defects caused by tumors, trauma or inflammation remains a major clinical challenge and tissue engineering is a promising technique for resolving this problem (6). Tissue engineering involves three main components: Multipotent stem cells, biocompatible and biodegradable
A

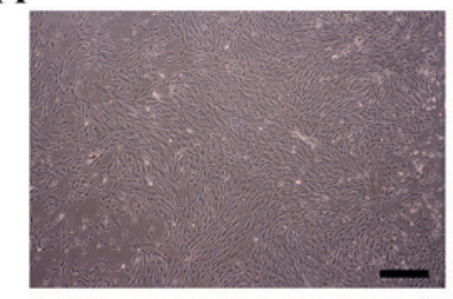

B

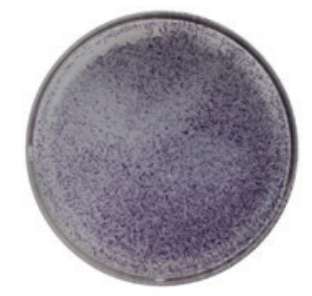

$\mathrm{C}$

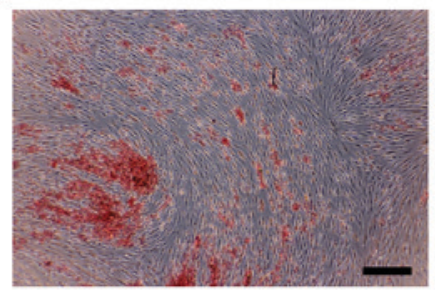

D

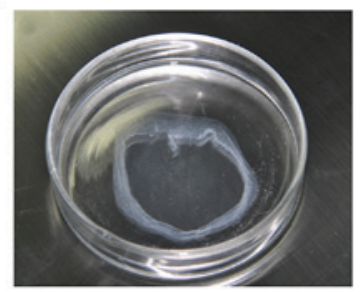

Figure 2. Osteogenic differentiation of MSCs in vitro and fabrication of the cell sheet. (A) Morphology of MSCs. (B) Osteoblastic differentiation of MSCs was evaluated on day 7 using alkaline phosphatase staining. (C) Osteoblastic differentiation of MSCs was evaluated on day 21 using Alizarin red staining. (D) MSCs were lifted as a cell sheet using a scraper. Scale bar=50 $\mu \mathrm{m}$. MSC, mesenchymal stem cell.

scaffolds and cytokines (38). Numerous attempts have been made to optimize protocols for bone tissue engineering $(39,40)$. In the present study, it was hypothesized that a process may be developed that incorporates MSC sheets with nano-HA and autologous PRF granules for enhanced bone formation within a rabbit CSD model. The results demonstrated that the MSC/PRF group regenerated significantly more bone within the defect and achieved greater bony bridging of the defect compared with the other two groups.

When comparing 3D CT images, different bone regeneration modes specific to the three groups were clearly observed. In the MSC/PRF group, bone regeneration was observed progressively throughout both the center and the edges of the defects. However, in the MSC group, bone formation occurred mainly from the periphery of the defect, leaving the center of the defect almost empty. In spite of this, by the end of the study the size of the defect was significantly smaller than its original size. These findings suggested that the presence of granular PRF may be an essential requirement for effective bone regeneration. In the control group, bone regenerated only at the edge of the defect, and there was no obvious reduction in the defect area. The histological and histomorphometry results supported those of the CT evaluation, suggesting that the MSC/PRF group achieved the best osteogenic healing effect. Compared with the MSC/PRF group, a sparser and smaller amount of new bone formation was observed in the MSC group, in particular in the center of the defect. At the end of the study, the defect was almost completely occupied with fibrous tissues in the control group.

In bone tissue engineering, the use of autologous bone marrow-derived mesenchymal stem cells as sources, combined with a biodegradable scaffold, is the golden standard (1). Bone marrow MSCs were first described by Friedenstein et al (41) and isolated by their adherence properties to plastic in tissue culture. One of the critical functions of MSCs is to support the process of bone remodeling by providing osteoblasts (42). 
A

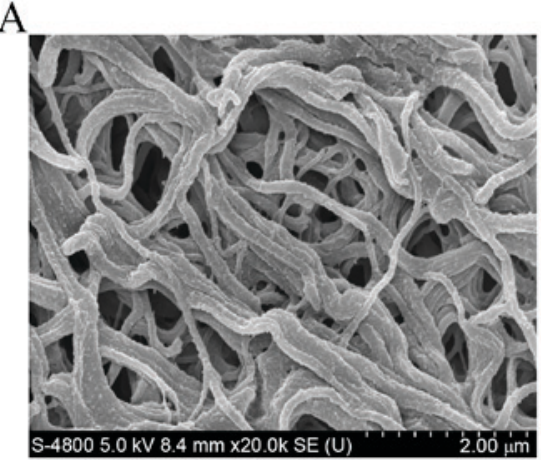

B

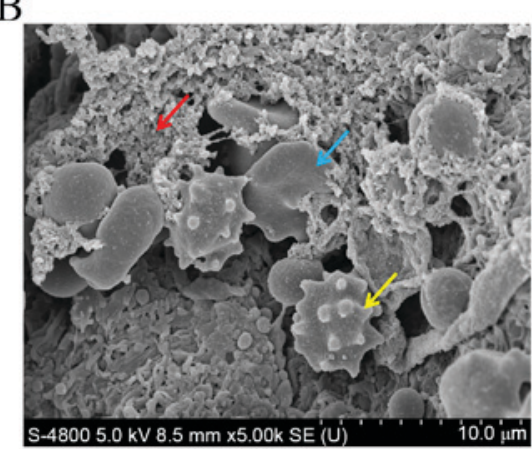

Figure 3. Scanning electron micrograph images of the PRF. (A) In the top region of the PRF, many fibrin fibers assembled to create a tight, porous three-dimensional fibrin network structure, in which few platelets or cells were visible. A coarse surface of fibrin strands was visible. (B) In the lower region of the PRF, numerous (red arrow) platelets, (yellow arrow) leukocytes and (blue arrow) red blood cells were embedded in the network. PRF, platelet-rich fibrin.

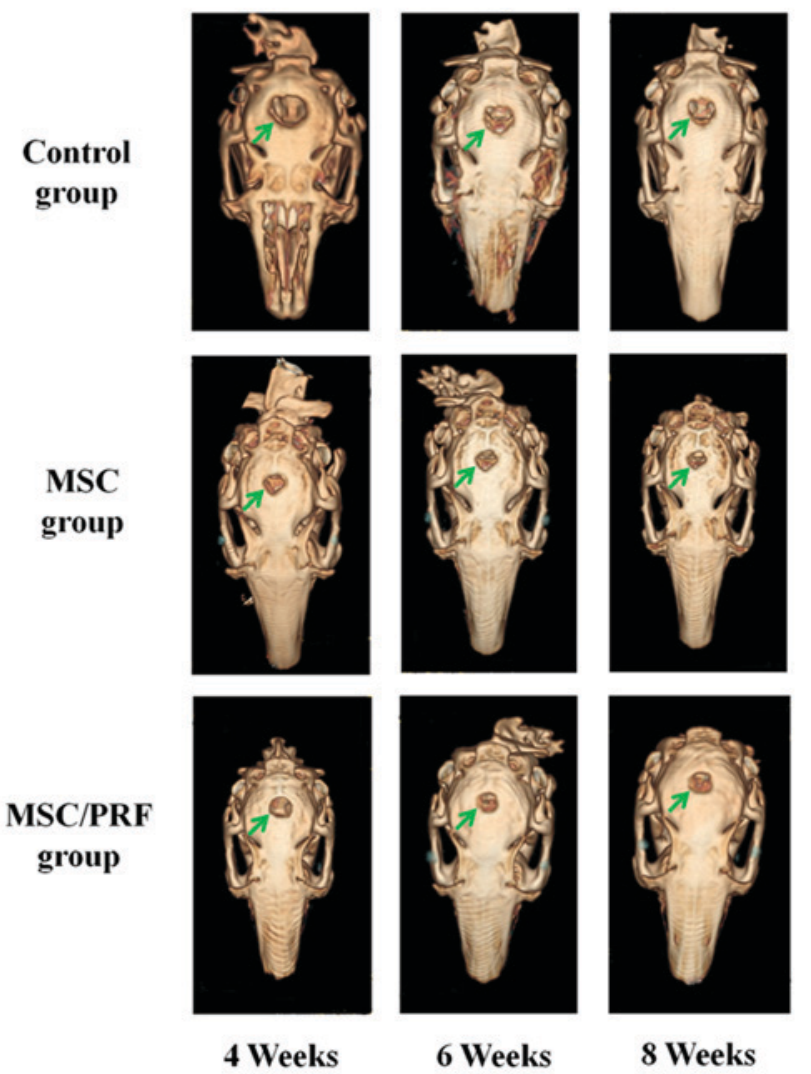

Figure 4. Three-dimensional CT analyses. Bone regeneration was intermittently monitored via CT scanning at 4,6 and 8 weeks post-surgery. A representative case of each group is displayed. Green arrows indicate the experimental area. CT, computed tomography; MSC, mesenchymal stem cell; PRF, platelet-rich fibrin.

In the present study, positive Alizarin red and ALP staining also demonstrated that rabbit MSCs were successfully induced into osteoblasts under the conditions of osteogenic medium. Additionally, MSCs have been positioned at the forefront of bone tissue engineering due to their other biological properties, including paracrine and immunoregulatory capabilities (43). A number of previous studies have indicated that the secretion of various trophic factors and cytokines may be a mechanism for use of MSCs in bone repair $(44,45)$. For instance, a broad

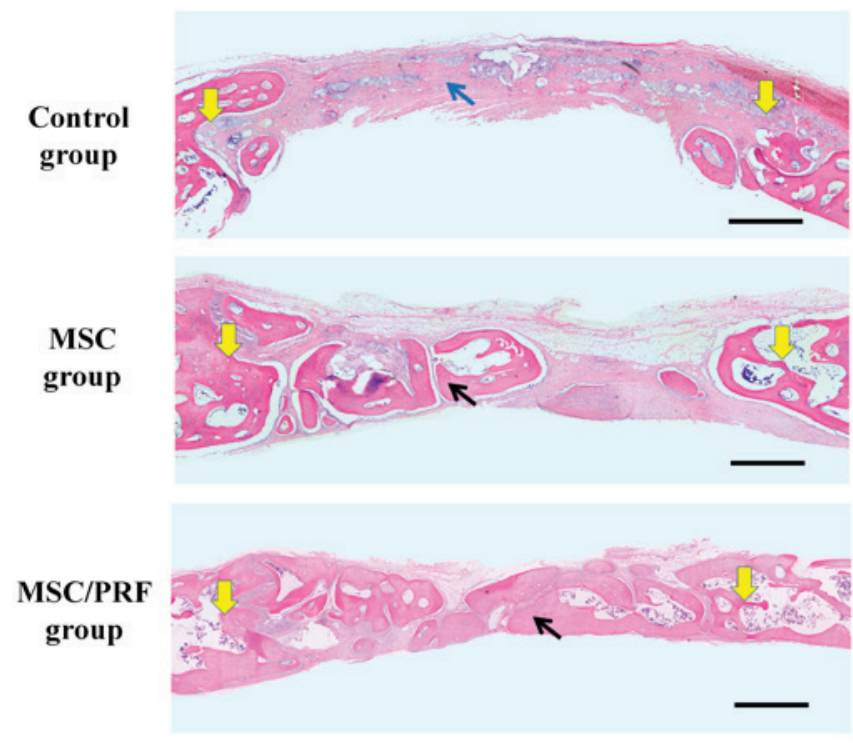

Figure 5. Histology of regenerated bone from the control and experimental groups. Rabbits were sacrificed 8 weeks post-operation. Regenerated tissue was subjected to paraffin embedding and sectioning. Hematoxylin and eosin staining were performed and magnified views are displayed (magnification, x5). Scale bar $=2 \mathrm{~mm}$. Yellow arrows indicate the edge of the defect (Black arrows). New bone formation was observed in the MSC/PRF and MSC group. However, (blue arrow) fibrous tissues were mostly observed in the control group. MSC, mesenchymal stem cell; PRF, platelet-rich fibrin.

repertoire of angiogenic factors have been detected in the secretome of MSCs, including vascular endothelial growth factor (VEGF), fibroblast growth factor-2, angiopoietin-1, monocyte chemoattractant protein -1, and interleukin (IL)-6 (8,45-48), which may be important in bone regeneration. The immunosuppressive effect of MSCs is well established in previous literature $(49,50)$. Specialized bioactive molecules secreted by MSCs may be able to prevent unfavorable immune reactions and provide support to repairing injured tissues (45). The local immunosuppressive actions of MSCs have also led to suggestions of allogeneic MSCs treatment in settings where the use of autologous cells is limited or even impossible (42).

The cell sheet technique was used to harvest cells and produce tissue-engineered bone. The application of cell sheets, as a scaffold-free cell delivery system, has previously been reported in the transplantation of MSCs to enhance the bone 


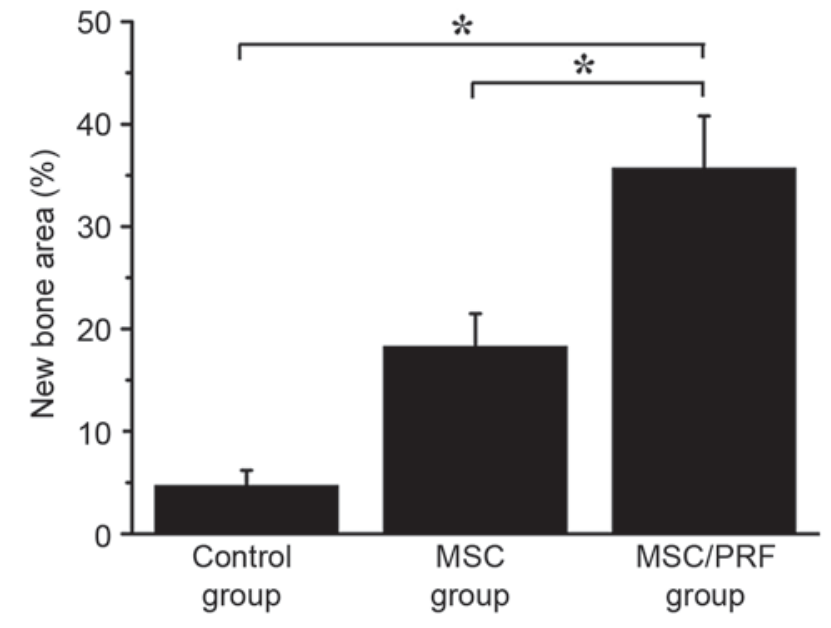

Figure 6. Percentage of new bone area in the defect site determined by histomorphometric image analysis in each group. Data are presented as the mean \pm standard deviation. ${ }^{*} \mathrm{P}<0.05$ vs. the MSC group and the control group. MSC, mesenchymal stem cell; PRF, platelet-rich fibrin.

formation $(16,19)$. The use of cell sheets has several advantages compared with current methods; firstly, as no invasive enzymatic treatment is used, the intact cell sheet is harvested along with its ECM, which is important for cell differentiation and bone formation (51). Secondly, the cell sheet also maintains cell-to-cell and cell-to-ECM connections, which are typically required for the creation of functional tissues (52). Adhesion molecules on the cell surface, cell-to-cell interactions, and cell interconnections with gap junctions, which mediate the reciprocal exchange of small molecules and proteins, were addressed in a previous study by the present authors (53). However, cell sheets also have an intrinsic shortcoming as they have poor mechanical strength, making them insufficient for larger defects (54). To overcome this, previous studies have utilized cell sheets reinforced with scaffold materials. Zhou et al (6), for example, used biodegradable scaffold-bone marrow stromal cell sheet complexes. Layered cell sheets wrapped in a polycaprolactone-tri-calcium phosphate scaffold were used to enhance in vivo bone formation. Such complexes possess good mechanical strength, so cell sheet techniques may provide a potential novel approach to bone tissue engineering. In the present study, nano-HA scaffolds were used to promote bone regeneration and maintain the initial shape and volume of cell sheets, which typically shrank spontaneously following detachment. Based on the literature, it appears that nanocrystalline HA powders have better biocompatibility, osteoinductivity, and even angioconductive potential compared with coarser crystals, due to their superior biological and biomechanical properties $(55,56)$. Additionally, Cai et al (57) demonstrated that MSCs prepared with nano-HA exhibited greater cell viability and proliferation properties compared with conventional HA. The cell sheet/nano-HA scaffold may therefore contribute to bone engineering due to its favorable mechanical properties, including toughness and plasticity from the cell sheet and strength from the nano-HA.

PRF belongs to a second generation of platelet concentrates, and was used as a source of growth factors in the current study. PRF is often defined as an autologous leukocyte-and platelet-rich fibrin (28) and has been widely used in maxillofacial and plastic surgery, and tissue-engineering paradigms (26,58-60). The results of the present study indicate that the PRF clot forms a mechanically strong fibrin matrix with a 3D architecture in which plenty of the platelets and leukocytes from the harvested blood are concentrated in the lower red region of the clot. This is concurrent with several previous reports $(34,61)$. Platelets are activated during the prepared process, which leads to a substantial embedding of platelet growth factors into the fibrin matrix (62), including platelet-derived growth factor, insulin-like growth factors, transforming growth factor $\beta$, VEGF and a myriad of other substances which promote bone healing. The PRF protocol also induced an increase in leukocyte degranulation (31). Many leukocyte growth factors, such as IL-1 $\beta$, IL-6, and tumor necrosis factor $\alpha$, were trapped in the fibrin networks during polymerization. With these cytokines contributing to anti-infectious action and immune regulation, the PRF clot may additionally be considered to be an immune organizing node. Following application, the strong fibrin matrix of PRF was slowly remodeled in a way similar to a natural blood clot (28) and growth factors were released in a controlled and progressive way (63-65). A previous study by the present authors (35) revealed that PRF growth factors were released in a time-dependent manner. Such a releasing pattern may result in longer-lasting biological effects, which initiate and foster bone regeneration. The results of the present study suggest that the use of PRF may offer an easy, cost-effective way to obtain high concentrations of growth factors and stimulate bone formation.

In the present study, a rabbit calvarial CSD model was used because it is a well-documented model for evaluating bony healing (66). It has previously been suggested that calvaria is an anatomic area of limited mechanical stress and relative stability of the surrounding structures, and so is an ideal candidate for the study of interactions between new bone constructs and in situ bone (67). Furthermore, the patterns of bone accretion and overall bone mass in rabbits during skeletal maturation are similar to those in humans (68). Hollinger and Kleinschmidt (36) defined a CSD as a $15-\mathrm{mm}$ defect in this animal. To create a more challenging environment for bone generation, the periosteum was also resected. The recommended method of blood collection from rabbits is debated and a cardiac puncture is often recommended (37). In the present study, whole blood was harvested from the central ear artery while the rabbit was restrained in a restraining box, a method previously used by Lee and Pripatnanont $(59,69)$.

The method of bone tissue engineering used in the present study offers several advantages compared with the current strategies used. Firstly, a cell sheet combined with nano-HA acted as a bioactive scaffold in this bone regeneration protocol. An ideal scaffold for bone tissue engineering is a matrix that acts as a temporary substrate, allowing cell growth and tissue development (15). The cell sheet/nano-HA scaffold mimics the structure and biological function of the native ECM in terms of both chemical composition and physical structure. The composite scaffold had a certain degree of mechanical strength and was able to fill the defect, and the scaffold may also be biodegradable past the endpoint of the current study. Secondly, granular PRF was used as the autologous growth factor carrier in the present study. PRF has been the focus of previous experimental and clinical studies $(35,70,71)$. However, as revealed by SEM in the present study, the structure of PRF 
was non-homogenous. In the centrifugation process, slow polymerization of collagen fibers in the blood formed a 3D network structure. Due to the centrifugal force, the cellular components of the blood were redistributed to the lower part of the tubes. Red blood cells pelleted at the bottom of the tube, whereas platelets, embedded into the fibrin matrix, lay between red blood cells and the fibrous structure of PRF. This suggests that the most functional section of the PRF was in the lower region of the fibrin clot, which may be referred to as the 'red tip' due to its adjacency to red blood cells, as it was able to provide numerous growth factors. Therefore, the PRF was cut into small pieces and mixed together to distribute the red tip and provide an even concentration of growth factors across the whole bone regeneration site.

There are several limitations to the present study. Micro-CT 3D imaging of the specimen was not performed due to a lack of equipment, and normal CT 3D imaging only provided a crude demonstration of the effect of bone regeneration in the three groups. Micro-CT may be able to provide more detailed pictures, and so this tool should be utilized in future research. Another limitation was the potential risk of using ex vivo expanded MSCs. The expansion of MSCs in this study used $\alpha$-MEM supplemented with $10 \%$ FBS, which may introduce the risk of contamination or adverse cellular changes $(72,73)$. Surgeons are hesitant to use a bovine derivative in human bone regenerative procedures as a number of reports have documented the development of anti-bovine antibodies that may cross-react with human clotting agents (72-74). In order to replace the FBS, and thus limit the potential re-implantation problems of cultivated MSCs, previous researchers have attempted to find some substitutes $(7,44)$. Notably, PRF has been suggested as a potential substitute (32). With technological advancements, this issue may eventually be resolved.

In conclusion, the combined application of an MSC sheet with nano-HA and granular PRF may provide a novel approach for bone tissue regeneration in large bone defects. Such a bone tissue engineering protocol would be a promising therapeutic strategy in bone regenerative medicine.

\section{Acknowledgements}

The present study was supported by the National Natural Science Foundation of China (grant nos. 31400839, 81400492 and 81402231).

\section{References}

1. Uchiyama H, Yamato M, Sasaki R, Sekine H, Yang J, Ogiuchi H, Ando $\mathrm{T}$ and Okano T: In vivo 3D analysis with micro-computed tomography of rat calvaria bone regeneration using periosteal cell sheets fabricated on temperature-responsive culture dishes. J Tissue Eng Regen Med 5: 483-490, 2011.

2. Giovanini AF, Deliberador TM, Gonzaga CC, de Oliveira Filho MA, Göhringer I, Kuczera J, Zielak JC and de Andrade Urban C: Platelet-rich plasma diminishes calvarial bone repair associated with alterations in collagen matrix composition and elevated CD34+ cell prevalence. Bone 46: 1597-1603, 2010.

3. Intini G: The use of platelet-rich plasma in bone reconstruction therapy. Biomaterials 30: 4956-4966, 2009.

4. Burstein FD, Simms C, Cohen SR, Work F and Paschal M: Iliac crest bone graft harvesting techniques: A comparison. Plast Reconstr Surg 105: 34-39, 2000.

5. Monaco AP: The beginning of clinical tolerance in solid organ allografts. Exp Clin Transplant 2: 153-161, 2004.
6. Zhou Y, Chen F, Ho ST, Woodruff MA, Lim TM and Hutmacher DW: Combined marrow stromal cell-sheet techniques and high-strength biodegradable composite scaffolds for engineered functional bone grafts. Biomaterials 28: 814-824, 2007.

7. Kretlow JD, Spicer PP, Jansen JA, Vacanti CA, Kasper FK and Mikos AG: Uncultured marrow mononuclear cells delivered within fibrin glue hydrogels to porous scaffolds enhance bone regeneration within critical-sized rat cranial defects. Tissue Eng Part A 16: 3555-3568, 2010

8. Porada CD, Zanjani ED and Almeida-Porad G: Adult mesenchymal stem cells: A pluripotent population with multiple applications. Curr Stem Cell Res Ther 1: 365-369, 2006.

9. Gazit D, Turgeman G, Kelley P, Wang E, Jalenak M, Zilberman Y and Moutsatsos I: Engineered pluripotent mesenchymal cells integrate and differentiate in regenerating bone: A novel cell-mediated gene therapy. J Gene Med 1: 121-133, 1999.

10. Kon E, Muraglia A, Corsi A, Bianco P, Marcacci M, Martin I, Boyde A, Ruspantini I, Chistolini P, Rocca M, et al: Autologous bone marrow stromal cells loaded onto porous hydroxyapatite ceramic accelerate bone repair in critical-size defects of sheep long bones. J Biomed Mater Res 49: 328-337, 2000.

11. Bianco P, Riminucci M, Gronthos S and Robey PG: Bone marrow stromal stem cells: Nature, biology, and potential applications. Stem Cells 19: 180-192, 2001

12. Quarto R, Mastrogiacomo M, Cancedda R, Kutepov SM, Mukhachev V, Lavroukov A, Kon E and Marcacci M: Repair of large bone defects with the use of autologous bone marrow stromal cells. N Engl J Med 344: 385-386, 2001.

13. Yamada Y, Ueda M, Hibi H and Nagasaka T: Translational research for injectable tissue-engineered bone regeneration using mesenchymal stem cells and platelet-rich plasma: From basic research to clinical case study. Cell Transplant 13: 343-355, 2004.

14. Meijer GJ, de Bruijn JD, Koole R and van Blitterswijk CA: Cell based bone tissue engineering in jaw defects. Biomaterials 29: 3053-3061, 2008.

15. Zhou H and Lee J: Nanoscale hydroxyapatite particles for bone tissue engineering. Acta Biomater 7: 2769-2781, 2011.

16. Jin H, Zhang K, Qiao C, Yuan A, Li D, Zhao L, Shi C, Xu X, $\mathrm{Ni}$ S, Zheng C, et al: Efficiently engineered cell sheet using a complex of polyethylenimine-alginate nanocomposites plus bone morphogenetic protein 2 gene to promote new bone formation. Int J Nanomedicine 9: 2179-2190, 2014.

17. Yang J, Yamato M, Shimizu T, Sekine H, Ohashi K, Kanzaki M, Ohki T, Nishida K and Okano T: Reconstruction of functional tissues with cell sheet engineering. Biomaterials 28: 5033-5043, 2007.

18. Ma D, Ren L, Liu Y, Chen F, Zhang J, Xue Z and Mao T: Engineering scaffold-free bone tissue using bone marrow stromal cell sheets. J Orthop Res 28: 697-702, 2010.

19. Nakamura A, Akahane M, Shigematsu H, Tadokoro M, Morita Y, Ohgushi H, Dohi Y, Imamura T and Tanaka Y: Cell sheet transplantation of cultured mesenchymal stem cells enhances bone formation in a rat nonunion model. Bone 46: 418-424, 2010.

20. Bohner M: Calcium orthophosphates in medicine: From ceramics to calcium phosphate cements. Injury 31 (Suppl 4): S37-S47, 2000

21. Wagoner Johnson AJ and Herschler BA: A review of the mechanical behavior of $\mathrm{CaP}$ and $\mathrm{CaP} /$ polymer composites for applications in bone replacement and repair. Acta Biomater 7: 16-30, 2011.

22. LeGeros RZ: Biodegradation and bioresorption of calcium phosphate ceramics. Clin Mater 14: 65-88, 1993.

23. Dorozhkin SV: Nanosized and nanocrystalline calcium orthophosphates. Acta Biomater 6: 715-734, 2010.

24. Kim ES, Park EJ and Choung PH: Platelet concentration and its effect on bone formation in calvarial defects: An experimental study in rabbits. J Prosthet Dent 86: 428-433, 2001.

25. Ito K, Yamada Y, Naiki T and Ueda M: Simultaneous implant placement and bone regeneration around dental implants using tissue-engineered bone with fibrin glue, mesenchymal stem cells and platelet-rich plasma. Clin Oral Implants Res 17: 579-586, 2006.

26. Liao HT, Chen CT, Chen CH, Chen JP and Tsai JC: Combination of guided osteogenesis with autologous platelet-rich fibrin glue and mesenchymal stem cell for mandibular reconstruction. J Trauma 70: 228-237, 2011.

27. Anitua E, Sanchez M, Nurden AT, Nurden P, Orive G and Andía I: New insights into and novel applications for platelet-rich fibrin therapies. Trends Biotechnol 24: 227-234, 2006. 
28. Dohan Ehrenfest DM, Rasmusson L and Albrektsson T: Classification of platelet concentrates: From pure platelet-rich plasma (P-PRP) to leucocyte- and platelet-rich fibrin (L-PRF). Trends Biotechnol 27: 158-167, 2009.

29. Eppley BL, Woodell JE and Higgins J: Platelet quantification and growth factor analysis from platelet-rich plasma: Implications for wound healing. Plast Reconstr Surg 114: 1502-1508, 2004.

30. Tong W, Glimcher MJ, Katz JL, Kuhn L and Eppell SJ: Size and shape of mineralites in young bovine bone measured by atomic force microscopy. Calcif Tissue Int 72: 592-598, 2003.

31. Dohan DM, Choukroun J, Diss A, Dohan SL, Dohan AJ, Mouhyi J and Gogly B: Platelet-rich fibrin (PRF): A second-generation platelet concentrate. Part III: Leucocyte activation: A new feature for platelet concentrates? Oral Surg Oral Med Oral Pathol Oral Radiol Endod 101: e51-e55, 2006.

32. Dohan Ehrenfest DM, Doglioli P, de Peppo GM, Del Corso M and Charrier JB: Choukroun's platelet-rich fibrin (PRF) stimulates in vitro proliferation and differentiation of human oral bone mesenchymal stem cell in a dose-dependent way. Arch Oral Biol 55: 185-194, 2010.

33. Shimizu T, Yamato M, Isoi Y, Akutsu T, Setomaru T, Abe K, Kikuchi A, Umezu M and Okano T: Fabrication of pulsatile cardiac tissue grafts using a novel 3-dimensional cell sheet manipulation technique and temperature-responsive cell culture surfaces. Circ Res 90: e40, 2002.

34. Dohan DM, Choukroun J, Diss A, Dohan SL, Dohan AJ, Mouhyi J and Gogly B: Platelet-rich fibrin (PRF): A second-generation platelet concentrate. Part I: Technological concepts and evolution. Oral Surg Oral Med Oral Pathol Oral Radiol Endod 101: e37-e44, 2006.

35. Zhao YH, Zhang M, Liu NX, Lv X, Zhang J, Chen FM and Chen YJ: The combined use of cell sheet fragments of periodontal ligament stem cells and platelet-rich fibrin granules for avulsed tooth reimplantation. Biomaterials 34: 5506-5520, 2013.

36. Hollinger JO and Kleinschmidt JC: The critical size defect as an experimental model to test bone repair materials. J Craniofac Surg 1: 60-68, 1990.

37. Dohan Ehrenfest DM, Lemo N, Jimbo R and Sammartino G: Selecting a relevant animal model for testing the in vivo effects of Choukroun's platelet-rich fibrin (PRF): Rabbit tricks and traps. Oral Surg Oral Med Oral Pathol Oral Radiol Endod 110: 413-418, 2010.

38. Langer R and Vacanti JP: Tissue engineering. Science 260: 920-926, 1993

39. Mattar P and Bieback K: Comparing the immunomodulatory properties of bone marrow, adipose tissue and birth-associated tissue mesenchymal stromal cells. Front Immunol 6: 560, 2015.

40. Yu X, Tang X, Gohil SV and Laurencin CT: Biomaterials for bone regenerative engineering. Adv Healthc Mater 4: 1268-1285, 2015.

41. Friedenstein AJ, Chailakhyan RK, Latsinik NV, Panasyuk AF and Keiliss-Borok IV: Stromal cells responsible for transferring the microenvironment of the hemopoietic tissues. Cloning in vitro and retransplantation in vivo. Transplantation 17: 331-340, 1974.

42. Bronckaers A, Hilkens P, Martens W, Gervois P, Ratajczak J, Struys T and Lambrichts I: Mesenchymal stem/stromal cells as a pharmacological and therapeutic approach to accelerate angiogenesis. Pharmacol Ther 143: 181-196, 2014.

43. Satija NK, Singh VK, Verma YK, Gupta P, Sharma S, Afrin F, Sharma M, Sharma P, Tripathi RP and Gurudutta GU: Mesenchymal stem cell-based therapy: A new paradigm in regenerative medicine. J Cell Mol Med 13: 4385-4402, 2009.

44. Kagami $\mathrm{H}$, Agata $\mathrm{H}$ and Tojo A: Bone marrow stromal cells (bone marrow-derived multipotent mesenchymal stromal cells) for bone tissue engineering: Basic science to clinical translation. Int J Biochem Cell Biol 43: 286-289, 2011.

45. Caplan AI and Correa D: The MSC: An injury drugstore. Cell Stem Cell 9: 11-15, 2011.

46. Kinnaird T, Stabile E, Burnett MS, Lee CW, Barr S, Fuchs S and Epstein SE: Marrow-derived stromal cells express genes encoding a broad spectrum of arteriogenic cytokines and promote in vitro and in vivo arteriogenesis through paracrine mechanisms. Circ Res 94: 678-685, 2004.

47. Wu Y, Chen L, Scott PG and Tredget EE: Mesenchymal stem cells enhance wound healing through differentiation and angiogenesis. Stem Cells 25: 2648-2659, 2007.

48. Chen L, Tredget EE, Wu PY and Wu Y: Paracrine factors of mesenchymal stem cells recruit macrophages and endothelial lineage cells and enhance wound healing. PLoS One 3: e1886, 2008 .
49. Del Papa N, Quirici N, Soligo D, Scavullo C, Cortiana M, Borsotti C, Maglione W, Comina DP, Vitali C, Fraticelli P, et al: Bone marrow endothelial progenitors are defective in systemic sclerosis. Arthritis Rheum 54: 2605-2615, 2006.

50. Nauta AJ and Fibbe WE: Immunomodulatory properties of mesenchymal stromal cells. Blood 110: 3499-3506, 2007.

51. Holtorf HL, Jansen JA and Mikos AG: Ectopic bone formation in rat marrow stromal cell/titanium fiber mesh scaffold constructs: Effect of initial cell phenotype. Biomaterials 26: 6208-6216, 2005

52. Yang J, Yamato M, Kohno C, Nishimoto A, Sekine H, Fukai F and Okano T: Cell sheet engineering: Recreating tissues without biodegradable scaffolds. Biomaterials 26: 6415-6422, 2005.

53. Wang X, Sha XJ, Li GH, Yang FS, Ji K, Wen LY, Liu SY, Chen L, Ding Y and Xuan K: Comparative characterization of stem cells from human exfoliated deciduous teeth and dental pulp stem cells. Arch Oral Biol 57: 1231-1240, 2012

54. Chen F, Zhou Y, Barnabas ST, Woodruff MA and Hutmacher DW: Engineering tubular bone constructs. J Biomech 40 (Suppl 1): S73-S79, 2007.

55. Stupp SI and Ciegler GW: Organoapatites: Materials for artificial bone. I. Synthesis and microstructure. J Biomed Mater Res 26: 169-183, 1992.

56. Appleford MR, Oh S, Oh N and Ong JL: In vivo study on hydroxyapatite scaffolds with trabecular architecture for bone repair. J Biomed Mater Res A 89: 1019-1027, 2009

57. Cai Y, Liu Y, Yan W, Hu Q, Tao J, Zhang M, Shi Z and Tang R: Role of hydroxyapatite nanoparticle size in bone cell proliferation. J Mater Chem 17: 3780-3787, 2007.

58. Granchi D, Devescovi V, Baglio SR, Magnani M, Donzelli O and Baldini N: A regenerative approach for bone repair in congenital pseudarthrosis of the tibia associated or not associated with type 1 neurofibromatosis: Correlation between laboratory findings and clinical outcome. Cytotherapy 14: 306-314, 2012.

59. Pripatnanont $\mathrm{P}$, Nuntanaranont T, Vongvatcharanon $\mathrm{S}$ and Phurisat K: The primacy of platelet-rich fibrin on bone regeneration of various grafts in rabbit's calvarial defects. J Craniomaxillofac Surg 41: e191-e200, 2013.

60. Xuan F, Lee CU, Son JS, Jeong SM and Choi BH: A comparative study of the regenerative effect of sinus bone grafting with platelet-rich fibrin-mixed Bio-Oss ${ }^{\circledR}$ and commercial fibrin-mixed Bio-Oss $®$ : An experimental study. J Craniomaxillofac Surg 42: e47-e50, 2014.

61. Tunali M, Özdemir H, Küçükodaci Z, Akman S and Firatlı E: In vivo evaluation of titanium-prepared platelet-rich fibrin (T-PRF): A new platelet concentrate. Br J Oral Maxillofac Surg 51: 438-443, 2013.

62. Dohan DM, Choukroun J, Diss A, Dohan SL, Dohan AJ, Mouhyi J and Gogly B: Platelet-rich fibrin (PRF): A second-generation platelet concentrate. Part II: Platelet-related biologic features. Oral Surg Oral Med Oral Pathol Oral Radiol Endod 101: e45-e50, 2006

63. Dohan Ehrenfest DM, de Peppo GM, Doglioli P and Sammartino G: Slow release of growth factors and thrombospondin-1 in Choukroun's platelet-rich fibrin (PRF): A gold standard to achieve for all surgical platelet concentrates technologies. Growth Factors 27: 63-69, 2009.

64. He L, Lin Y, Hu X, Zhang Y and Wu H: A comparative study of platelet-rich fibrin (PRF) and platelet-rich plasma (PRP) on the effect of proliferation and differentiation of rat osteoblasts in vitro. Oral Surg Oral Med Oral Pathol Oral Radiol Endod 108: 707-713, 2009.

65. Liu B, Tan XY, Liu YP, Xu XF, Li L, Xu HY, An R and Chen FM: The adjuvant use of stromal vascular fraction and platelet-rich fibrin for autologous adipose tissue transplantation. Tissue Eng Part C Methods 19: 1-14, 2013.

66. Schmitz JP and Hollinger JO: The critical size defect as an experimental model for craniomandibulofacial nonunions. Clin Orthop Relat Res: 299-308, 1986.

67. Costa Ade M, Kobayashi GS, Bueno DF, Martins MT, Ferreira Mde C, Passos-Bueno MR and Alonso N: An experimental model for the study of craniofacial deformities. Acta Cir Bras 25: 264-268, 2010

68. Djasim UM, Wolvius EB, van Neck JW, Weinans H and van der Wal KGH: Recommendations for optimal distraction protocols for various animal models on the basis of a systematic review of the literature. Int J Oral Maxillofac Surg 36: 877-883, 2007.

69. Lee EH, Kim JY, Kweon HY, Jo YY, Min SK, Park YW, Choi JY and Kim SG: A combination graft of low-molecular-weight silk fibroin with Choukroun platelet-rich fibrin for rabbit calvarial defect. Oral Surg Oral Med Oral Pathol Oral Radiol Endod 109: e33-e38, 2010. 
70. Zhang Y, Tangl S, Huber CD, Lin Y, Qiu L and Rausch-Fan X: Effects of Choukroun's platelet-rich fibrin on bone regeneration in combination with deproteinized bovine bone mineral in maxillary sinus augmentation: A histological and histomorphometric study. J Craniomaxillofac Surg 40: 321-328, 2012.

71. Li Q, Pan S, Dangaria SJ, Gopinathan G, Kolokythas A, Chu S, Geng Y, Zhou Y and Luan X: Platelet-rich fibrin promotes periodontal regeneration and enhances alveolar bone augmentation. Biomed Res Int 2013: 638043, 2013.

72. Boquest AC, Shahdadfar A, Frønsdal K, Sigurjonsson O, Tunheim SH, Collas P and Brinchmann JE: Isolation and transcription profiling of purified uncultured human stromal stem cells: Alteration of gene expression after in vitro cell culture. Mo Biol Cell 16: 1131-1141, 2005.
73. Lepperdinger G, Brunauer R, Jamnig A, Laschober G and Kassem M: Controversial issue: Is it safe to employ mesenchymal stem cells in cell-based therapies? Exp Gerontol 43: 1018-1023, 2008.

74. Lawson JH: The clinical use and immunologic impact of thrombin in surgery. Semin Thromb Hemost 32 (Suppl 1): S98-S110, 2006. 